\title{
THE QUALITY OF UNDERGRADUATE AND POSTGRADUATE TRAINING OF A TEACHING ASSISTANT
}

\author{
Jan Michalík \\ Jiř́ Langer \\ Institute of Special Education Studies, Palacký University Olomouc, \\ Czech Republic
}

\begin{abstract}
The article deals with the results of research, monitoring the attitudes of specific pedagogical staff - teaching assistants (TA) - in the Czech Republic to their undergraduate and postgraduate education. It includes statements of more than 800 respondents. It evaluates the qualifications, teaching assistants' skills of working with children of the target group (disablements and social disadvantages). It provides a comparison of attitudes of both teaching assistants' groups (acting as teaching assistants in two mentioned groups of pupils). It answers the questions: Which qualifications are regarded by TA as the most important? Which skills have not been provided by existing training programs and courses? How do they assess the conditions of executing the profession in schools? The research confirmed the difference between legislatively determined mandatory minimum of educational curriculum for TA and their real needs. It makes proposals to modify training programs.
\end{abstract}

Keywords: pedagogical staff, teaching assistants, pupil with disability, socially disadvantaged pupil, special educational needs, curriculum.

\section{Introduction}

In the Czech Republic there are more than five thousand teachers working as teaching assistants at schools. Formally, such a post was established in 2005, within the meaning of the Education Act 2004 and the prerequisites for this professional position brought Pedagogical Staff Act 2004. By 2005, assistants worked at schools - but unsystematically, mostly "hidden" under a different pedagogical position (educator, a worker in the so-called civil-service compensation for military service, etc.).

During nearly ten years of the official activities of teaching assistants they have proven to be an irreplaceable contribution to the education of children, pupils and students (hereinafter pupils) with special educational needs. On the other hand, experience has shown a number of challenges the profession faces. Some of them have a common basis and impacts on the whole territory of the Czech Republic (eg. absence of uniform rules of the establishment of this position, the lack of methodological guidance and, finally, the lack of generally accepted standards of TA activities). Others are relevant to the region or school (especially misunderstanding of the role and place of the TA in the team of teachers). Many of them, however, appear also in other countries (Ross, Dunphy, 2007)

However, inconsistencies between the activities of teaching assistants and the differences in their preparation (and acquired competences) fall the most to the primary users of their services - students in classes in which an assistant operates. (Uzlova, 2010) 
In the Czech Republic there is currently a team of experts preparing a system solution of aspects of the performance of this job for the Ministry of Education. In this project ${ }^{1}$ there are gradually emerging:

a) TA work standards

b) Education system design for TA

c) Financing system design for TA

In this paper we bring a part of a sub-product "TA Training Analysis in the Czech Republic." We focus on the parts that can be beneficial for the international community.

\section{Education of a teaching assistant}

Basic training requirements are provided in the relevant legislation Section 20 of the Pedagogical Staff Act 2004. By law the qualification can be obtained for the "expert" teaching assistant - or "auxiliary" teaching assistant in the following ways.

Sect. 1)

a) university education obtained by studying in the field of pedagogical science,

b) other university education than under letter a) and

1. education in the Lifelong Learning Programme (LLP hereinafter) at university and focused on education,

2. study pedagogy, or

3. completion of a training program for teaching assistants at a university or facilities for further education of teachers

c) higher vocational education at a vocational school in pedagogy,

d) other higher vocational education than under letter c) and

1. education in LLP at a university focused on pedagogy,

2. studying pedagogy, or

3. studies for teaching assistants.

e) secondary education with a school-leaving examination in pedagogy, or

f) other secondary education with a school-leaving examination than under letter

e) and

1. education in LLP at a university focused on pedagogy,

2. studying pedagogy, or

3. studies for teaching assistants.

These "studies" for teaching assistants can also be completed in a special form of an accredited program of 80 hours of instruction and 40 hours of practice. This is criticized as inadequate.

Sect. 2)

A teaching assistant who performs a direct educational activity of auxiliary educational work at school, gaining professional qualifications in addition to the

\footnotetext{
1 Systémová podpora inkluzivního vzdělávání v ČR (System support for inclusive education in the Czech Republic, CZ.1.07/1.2.00/43.0003), head researcher Jan Michalík.
} 
aforementioned, as follows:

a) secondary education with a vocational certificate and the study of pedagogy,

b) secondary education in the field of education focusing on preparing teaching assistants,

c) secondary education by completing an educational program of secondary education and

1. pedagogy studies, or

2. teaching assistant studies, or

d) basic education and a course for teaching assistants.

The quantitative dimension effect of teaching assistants in Czech schools (Kol. Autorů, 2013)

Number of TA in Czech schools

\begin{tabular}{|c|c|c|c|c|}
\hline Year & \multicolumn{2}{|c|}{ Individuals } & \multicolumn{2}{|c|}{ Conversion to full-time } \\
\hline 2005 & \multicolumn{2}{|c|}{1588} & \multicolumn{2}{|c|}{1156,4} \\
\hline 2006 & \multicolumn{2}{|c|}{2132} & \multicolumn{2}{|c|}{1559,9} \\
\hline 2007 & \multicolumn{2}{|c|}{2923} & \multicolumn{2}{|c|}{2098,9} \\
\hline 2008 & \multicolumn{2}{|c|}{3450} & \multicolumn{2}{|c|}{2415,4} \\
\hline 2009 & \multicolumn{2}{|c|}{4044} & \multicolumn{2}{|c|}{2772,3} \\
\hline 2010 & \multicolumn{2}{|c|}{4751} & \multicolumn{2}{|c|}{3145,6} \\
\hline 2011 & \multicolumn{2}{|c|}{5386} & \multicolumn{2}{|c|}{3483,1} \\
\hline \multirow{3}{*}{2012} & \multicolumn{2}{|c|}{6576} & \multicolumn{2}{|c|}{4276,5} \\
\hline & $\begin{array}{l}\text { TA for children } \\
\text { /pupils with ZP }\end{array}$ & $\begin{array}{l}\text { TA for children } \\
\text { /pupils with SZV }\end{array}$ & $\begin{array}{c}\text { Disab.- } \\
\text { conversion to } \\
\text { full-time }\end{array}$ & $\begin{array}{l}\text { SZV-Conversion } \\
\text { to full-time }\end{array}$ \\
\hline & 5966 & 610 & 3797,1 & 479,4 \\
\hline
\end{tabular}

* MŠMT data (ÚIV since 2011) come from the so called opening statements processed to 30 Sept. of the relevant year for the given school year.

** In the school year 2010/2011 there were app. 330 thousand children in the preschool education, at elementary schools (4123 ZŠ) were 789 thousand pupils and at secondary schools (1423 schools) were 497 thousand students in the day form of education.

*** $\mathrm{ZP}=$ health disability and $\mathrm{SZV}=$ socially disadvantaged

\section{Methodology}

Given the large number of members of a core set of teaching assistants working in schools in the Czech Republic (see above), quantitatively conceived collection of empirical data and their subsequent statistical processing were chosen. The form of an online questionnaire that allows remote access of respondents to the questionnaire and filling in on-line mode was chosen. 
I was preceded by piloting with teaching assistants working with different target groups of children with SEN, with different terms and practices in different regions of the country. The findings of the pilot pilot-study were subsequently taken into account. The measuring instrument was structured into four thematic areas (professional qualifications, current job, the position of assistant teacher at the school, socio-demographic characteristics). A total of 30 research respondents asked questions (11 semi-structured selection, 9 unstructured, 5 scale and 5 dichotomous), to some of which mandatory response was required. At the end of the questionnaire respondents were free to comment on the issue of their profession as a teaching assistant.

\section{Description of the sample}

The research sample consisted of a total of 838 respondents working in a job teaching assistant for pupils with special educational needs. The investigation was attended by 785 women (94\%) and 53 men (6\%), which corresponds to the usual gender representation of teachers in the Czech education system. The age range of respondents- teaching assistants was between 19 to 71 years. Most respondents were aged 39 years (5\% of the total set), while the average age of respondents was 38.4 years.

In terms of education the largest group was with completed secondary school graduates $(53 \%)$, followed by respondents with a university education $(27 \%)$, trained without GCE (10\%) and higher specialized education (9\%). 1\% (total 10) teaching assistants has a basic education. From the perspective of practice respondents working as teaching assistants were the most numerous category of $2-5$ years and over 5 years (both $28 \%$ ), with length of service within one year $(26 \%)$ and $1-2$ years $(18 \%)$.

In terms of the area of action of the respondents it can be said that the investigation involved teaching assistants more or less evenly from all territorial units (14 regions), with the exception of the Pilsen region.

In terms of target groups TA worked with students with disabilities (686 respondents), physical handicap (30 respondents) and socially disadvantaged pupils (122 respondents). That ratio corresponds to the nationwide situation (see above). From the category of disability it is to the greatest extent pupils with autistic spectrum disorders, learning disabilities, ADHD and children with mental disabilities.

\section{Research objective}

The aim of the research was to determine whether the evaluation of the adequacy of vocational training and basic markers of its performance there are statistically significant differences between TA acting for pupils with disabilities and handicaps and TA for socially disadvantaged pupils. 
In the Czech Republic the issue of education of children and pupils who come from socially disadvantaged backgrounds is becoming increasingly important. In the past, many of them were placed in schools for pupils with disabilities (mental) disability. Currently, there is a strong pressure of parental and nongovernmental organizations to ensure their education in mainstream schools. The presence of TA is seen as crucial. The finding whether there are differences between the two TA groups in the evaluation of monitored items is crucial for the correct setting educational model for the future.

To achieve the objectives of the research it was decided to research the correlation analysis of quantitative data through the test of the statistical significance of the chi-square for the PivotTable. Given the above formulated research problem an item finding, in which the target groups of pupils with special educational needs the individual respondents of the research work was correlated with other items. For the purposes of this paper categories of TA for a student with disabilities and SZN were merged into one single category comprising a total of 716 respondents $(86 \%)$. The second group consists of teaching assistants for pupils with social disadvantage.

For the purpose of this paper the following items were chosen from the extensive whole of the electronic questionnaire items:

- How did you obtain professional qualifications of the teaching assistant?

- What is your highest level of education attained?

- What skills do you think are the most important for the profession of TA?

- In what areas of competence of your profession do you feel that you lack the necessary educational preparation?

- How do you assess your readiness to work with this group of pupils gained through education?

\section{Results \\ Qualification level of teaching assistants}

First, the correlation data analysis examined whether there are statistically significant differences in the erudition of the two groups of teaching assistants. Substituting this into the pivot table, it was found out that according to the goodness of fit chi-square for the PivotTable at a significance level of 0.05 there are no statistically significant differences between the two groups in the number of assistants required with erudition and without erudition, as there are no statistically significant differences in the types of acquisition erudition for the profession of a teacher assistant. 


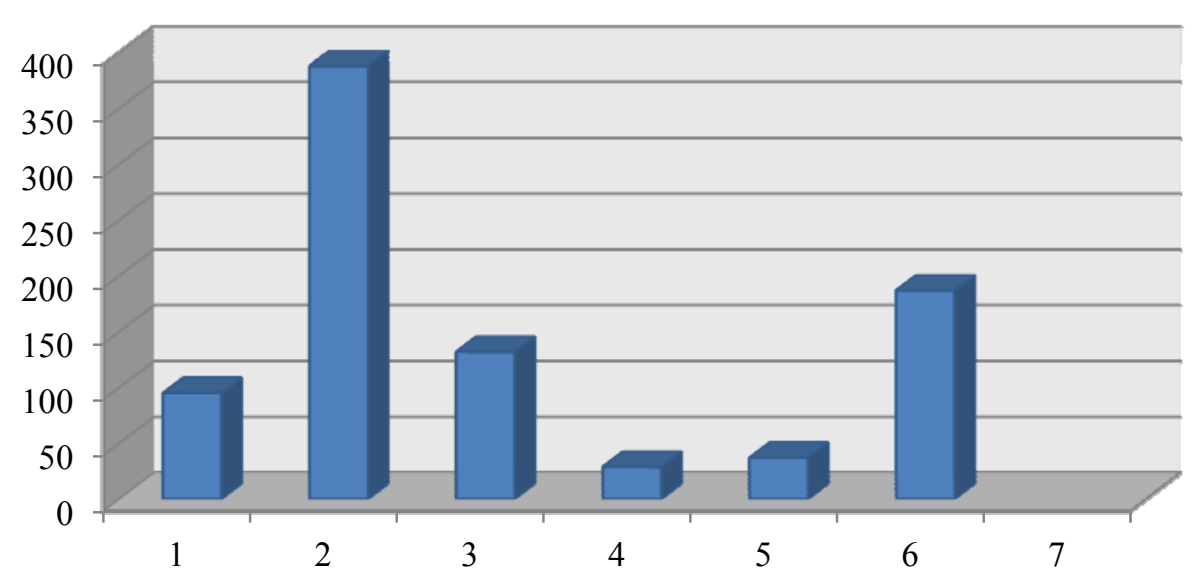

Figure 1 A method for obtaining qualification for the profession of a TA

1 - without qualification; 2 - accredited course for teaching assistant; 3 - secondary education in pedagogy; 4 - secondary education for education staff; 5 - higher vocational education for teaching assistant; 6 - university study program in pedagogical science; 7 - others

\section{The highest achieved education}

A statistically significant difference between the two groups of teaching assistants demonstrated a correlation with the item detecting the highest educational attainment of respondents. According to the sign test, the biggest differences are particularly apparent in the case of respondents with primary education, which is highly prevalent among teaching assistants for pupils with social disadvantage.

Table 2

Contingency table with the calculation of $\chi 2$ test of independence

\begin{tabular}{|l|c|c|c|c|c|c|c|}
\hline \multirow{4}{*}{$\begin{array}{l}\text { Target } \\
\text { group }\end{array}$} & \multicolumn{7}{|c|}{ The highest achieved education } \\
\cline { 2 - 8 } & & elementary & $\begin{array}{c}\text { aprenticeship } \\
\text { without GCE }\end{array}$ & $\begin{array}{c}\text { High school } \\
\text { with GCE }\end{array}$ & $\begin{array}{c}\text { Higher } \\
\text { professional }\end{array}$ & university & Total \\
\cline { 2 - 9 } & SZn and & 3 & 68 & 387 & 71 & 187 & $\mathbf{7 1 6}$ \\
& $\mathrm{SZn}$ & 7 & $(68,35)$ & $(378,51)$ & $(67,5)$ & $(193,1)$ & \\
\cline { 2 - 9 } & & $(1,46)$ & $(11,65)$ & $(64,49)$ & $(11,5)$ & 39 & $\mathbf{1 2 2}$ \\
& Total & $\mathbf{1 0}$ & $\mathbf{8 0}$ & $\mathbf{4 4 3}$ & $\mathbf{7 9}$ & $\mathbf{2 2 6}$ & $\mathbf{8 3 8}$ \\
\hline
\end{tabular}

\section{Evaluation of TA readiness for the profession}

In the correlated item finding its own self-evaluation of teaching assistants (using a five-point rating scale Lickert type) in readiness for the work with entrusted pupils were between the two groups statistically significant differences. Sign test also showed that the slight differences occur in the case of self-assessment score 2 (second highest), which in the case of assistants for pupils with disabilities or physical handicaps more frequent than the expected frequency. 
Evaluation of the readiness to work with students of the target group

\begin{tabular}{|l|c|c|}
\hline $\mathbf{1}-$ excellent & 185 & $22 \%$ \\
\hline $\mathbf{2}-$ very good & 410 & $49 \%$ \\
\hline $\mathbf{3}$ - good & 193 & $23 \%$ \\
\hline $\mathbf{4}-$ sufficient & 37 & $4 \%$ \\
\hline $5-$ insufficient & 13 & $2 \%$ \\
\hline
\end{tabular}

\section{Assessment of competencies for the profession}

Statistically significant differences between the two groups of teaching assistants present in the evaluation of the relevance and necessity of the specific competencies of teaching assistants working with students of the target group. The differences are particularly manifested in these key competencies:

- methods of work with pupils with special educational needs (prevalence among teaching assistants for pupils with disabilities or physical handicaps);

- forms of student involvement in the activities of the entire class (prevalence among teaching assistants for pupils with disabilities or physical handicaps).

Differences are not evident in these key competencies: safety awareness and legislation; communication skills; work with behavioral disorders; working with learning disabilities; communication with the family of the pupil; work with classroom climate; cooperation and communication with the teacher.

Similarly, statistically significant differences in the responses of both groups of respondents to the question, which should critically assess in which competencies they are feeling the deficits in their own educational preparation were confirmed. The differences are reflected in the following key competencies:

- safety awareness and legislation (prevalence among teaching assistants for pupils with disabilities or physical handicaps);

- Communication with the family of the pupil (predominated by teaching assistants socially disadvantaged pupils);

- forms of student involvement in the activities of the entire class (predominated by teaching assistants socially disadvantaged pupils).

Differences are not evident in these key competencies: safety awareness and legislation; communication skills; work with behavioral disorders; working with learning disabilities; communication with the family of the pupil; work with classroom climate; cooperation and communication with the teacher. 


\section{TA comments on professional training}

Property measuring tools enable respondents open expression of opinions, judgments and needs. Wide spectrum of responses was recorded (option used by 765 respondents), views that can be described as simplistic are presented without further comments:

„,Most of the practical knowledge gets one while working in specific facilities. It is not possible to get full complete knowledge of all variants of disability and target groups of students in a course; you would have to study special education."

"I'm a Roma, I understand the community. So I think that nothing will surprise me and I don't lack anything.

"I think education is insufficient for TA. I very much appreciated the opportunity for further education such as learning, as well as various seminars. Furthermore, I would like to see more books for TA activities, also a possibility of seminars with insights and advice of other assistants. "

\section{Evaluation of operating conditions of TA at school}

A substantial portion of the opinions concerned the evaluation of their impact on schools. The most frequent opinions referring to underpaid teaching assistants (TA salary is about 350-500 EUR, the average wage in the country is about 900 EUR) and the system is undocked in the education system:

"When I started, nobody really knew what the assistant is allowed to do and what is not, and it's still the same - can he teach in a class by himself - if not, why do they substitute for absent teachers, etc. Each director imagines assistant's work differently and the job description at each school is different - it needs to be uniformed."

"I enjoy the work of an assistant!! I do not know about other schools but at our school, the profession is treated as inferior. I'm just a mere assistant ... My work, and the fact that I'm helping, fills me. The greatest reward for me is progress in children. Those smiles that I receive! Fortunately, our school teachers took me in. From other schools I know that some teachers take it rather as some supervision and assistants are not recognized well. My job description in the contract does not correspond with the work they do!! Our rule is a lot of work for little money. I think that we should know how much money is coming to an assistant or even if the salary is somehow compensated, or if they give us only the necessary basic money. I currently work part-time and I have far less than living wage!"

"It is sad that this profession lacks money, yet it is a very meaningful and needed work. Assistants never know if the region will have money to give them, or if they remain without work."

\section{Discussion}

The selected items for teaching assistants of both groups (TA for a student with disabilities in TA pupils with SZN) showed statistically significant differences. Rating of the necessary skills and self-evaluation of key competencies provide a 
range of data that must be reflected in undergraduate and postgraduate training of teaching assistants.

Differences in methods of assessing the significance of the work, which research has shown are the result of natural differences between the two disadvantages (health vs. social). It is the development of specific forms of work with pupils eg. with sensory disabilities and for students with mental disabilities that is the reason why the TA of this group rated their preparedness more critically than the pupils with SZN. Undergraduate and postgraduate training must reflect this fact more. Another item that significantly more accentuated TA for pupils with disabilities is "forms of involvement of students with disabilities" in class activities. Indirectly, it can be concluded that the individual integration, which in this case is concerned, it is just a formal "placement" of a child in the class without becoming a full member of the class group.

If both groups of TA value the same as an important part of their own competencies the communication skills with the family of the pupil, then assistants for pupils with SZN assess readiness for this area critically. The reason is the situation of these children in schools, the specifics of their handicap. It has in the overwhelming majority its origins in the family - and its atmosphere, options, or socioeconomic status. Communication with parents is for the TA with SZN critical. It has a significant impact on families interested in learning about the efforts of children. Proper communication can improve the relationship between the family and the student to the school itself, increase the academic performance of children and on the other hand, limit the risk of early ending of education.

The results of the research also showed the need for a different approach to training for TA for ZP and TA for SZN. Profession of TA for SZN (which include pupils from socially disadvantaged families, students from socially nonstimulating environment, students of ethnic and national minorities, etc.) are relatively more dedicated assistants coming from the same environment as their students (whereas the TA for ZP in majority of cases do not have a disability). Therefore a lower level of education than in the case of teaching assistants for pupils with disabilities is assumed in TA for SZN. At undergraduate and postgraduate training of such assistants as well as in their methodology it is therefore necessary to apply such training and management approaches that will adequately reflect the situation.

From the perspective of key competencies in working as an assistant teacher, the two groups differ primarily in the area of specific educational methods and approaches to work with a pupil with special educational needs. This difference can be interpreted as a consequence of different communication needs (particularly in the case of pupils with sensory disabilities), respectively learning processes (especially for students with intellectual disabilities, learning disabilities, autism spectrum disorders etc.) of students with disabilities, compared with the majority intact population. By their own comments TA for 
students with disabilities quite often encounter communication barriers due to lack of knowledge of specific communication systems. Within specialized postgraduate training it is therefore necessary to provide competent assistants with the opportunity to increase their level of communication skills in various communication systems.

The measured differences in training assessment, given some of the key competencies show a greater emphasis of teaching assistants for pupils with social disadvantage on the need of enhancing training in the communications of teaching assistant with the family of the pupil, possibly in the strategies of involvement of pupils in the whole class activities. What resonates here is especially awareness of our own shortcomings in these competencies stemming probably from occasional failure in their respective situations. In the case of teaching assistants for pupils with disabilities or physical handicaps, it is primarily focus on the issue of ensuring the safety of pupils and the relevant legislation which stems from the relatively numerous experiences of assistants in ensuring the individual personal needs of entrusted students, such as medication, helping with separate movement, hygiene, etc. It was confirmed that TA usually have the need to improve their knowledge of legislation on liability for damages (for example) on the health of students and related issues.

The investigation also confirmed that, generally known information about the low level of salaries for TA activities have an impact not only on the individual experience of the profession and the degree of identification with it. To do this, cf. TA opinions mentioned above. However, they have their crucial meaning for support system for pupils with SEN in the Czech education system. Mentioned low salary motivation often leads to frequent departures from the position of TA. It is perceived as a "temporary" or "transitional" - to get a full teaching qualification, or vice versa as the "final" - after the previous active pedagogical action. The expenses on salaries of TA throughout the education system represent about 30 million EUR. It is desirable that the relatively high cost brought effective result. The education system can not change the salary, but may, with good settings, prepare the TA for more degrees of competence. This can in turn bring greater differentiation in pay.

\section{Conclusion}

The measured results show a brief slice of a large problem which is the effect of teaching assistants (especially) in transforming educational systems of countries of the so called former Eastern Europe. The association is particularly essential with a gradually increasing number of children with special education needs in mainstream primary education. Also there is an increasing demand on the number of teaching assistants in the terrain (schools, parents). As part of an extensive investigation the conclusion pledged for a unified approach to the profession of TA (regardless of students'control group). This uniformity of action can not hide the differences demonstrated in this investigation and that 
the two groups show. It is the specific requirements pertaining to the content of training - a profession-specific differences in the groups of students with disabilities and students with SZN.

As part of further work a team of researchers shall propose a new model for the Ministry of Education for TA training, which will include:

a) Modification of qualifying education and training opportunities

b) Modify the contents of the training program of training course in the undergraduate and postgraduate levels of TA education

c) Extension of the statutory range (hours) of training program course for the TA qualification

d) Within the formed TA Standard concerning the division of competences into three stages according to the demands of performance and thus the requirements for professional level training - qualification.

\section{References}

1. Balshaw, M.+ Farrel, P. (2013). Teaching assistant. New York: Routledge.

2. Burnham, L.; Carnpeter, K. (2004). The teaching assistants handbook. Oxford: Heinemann educational publishing.

3. Drake, P.; Jacklin, A. (2005). Becoming a Teaching Assistant. London: Paul ChTAman Publishing.

4. Team of authors. (2013). Asistent pedagoga, analýza personálnich, legislativních, statistických a procedurálnich aspektů. Olomouc: PdF UP.

5. Richards, G.; Armstrong, F. (2007). Key issues for teaching assistants. New York: Routletge.

6. Ross, C.; Dunphy, J. (2007). Strategies for teaching assistants development. San Francisco: Jossey-Bass.

7. Uzlová, I. (2010). Asistence lidem s postižením a znevýhodněním. Praha: Portál.

\section{Sources}

8. Systémová podpora inkluzivního vzdělávání v ČR (System support for inclusive education in the Czech Republic, CZ.1.07/1.2.00/43.0003), head researcher Jan Michalík.

9. Act No. 561/2004 Collection of Law, on Pre-school, Basic, Secondary, Tertiary Professional and Other Education (the Education Act) 2004

10. Act No. 563/2004 Collection of Law, on Pedagogical Staff and on the Amendment to Some Other Acts 2004

$\begin{array}{ll}\text { Jan Michalík } & \text { Institute of Special Education Studies, Palacký University } \\ & \text { Olomouc, Czech Republic } \\ & \text { Email:jan.michalik@upol.cz } \\ \text { Jiří Langer } & \text { Institute of Special Education Studies, Palacký University } \\ & \text { Olomouc, Czech Republic } \\ & \text { Email: jiri.langer@upol.cz }\end{array}$

